\title{
Isolation and Characterization of Antibiotic NC0604, a New Analogue of Bleomycin
}

\author{
Caixia Chen, Shuyi Si, Qiyang He, Hongzhang Xu, Min Lu, Yunying Xie, Yan Wang, \\ Ruxian Chen
}

Received: September 11, 2008 / Accepted: November 20, 2008

(C) Japan Antibiotics Research Association

\begin{abstract}
NC0604, a new analogue of bleomycin, was isolated from fermentation broth of Streptomyces verticillus var. pingyangensis n.var. The structure of NC0604 was elucidated by spectroscopic analyses. NC0604 had the same kernel structure as bleomycin, but a different terminal amine moiety determined as amidepropyl spermidine. NC0604 exhibited antibacterial activity against a wide range of bacterial species and showed cytotoxicity in vitro against human $\mathrm{HepG}_{2}$, KB, MCF-7, HCT116, BGC-823 and MCF-7/DOX cells with $\mathrm{IC}_{50}$ values of 1.18, 1.21, 1.41, $1.83,2.02,1.45 \mu \mathrm{M}$, respectively. The antitumor activity of NC0604 against these cells was $3 \sim 9$ times higher than that of bleomycin; and the pulmonary toxicity of $\mathrm{NC} 0604$ was much lower than that of bleomycin.
\end{abstract}

Keywords NC0604, structure elucidation, biological activity, pulmonary toxicity, bleomycin

NC0604, a new analogue of bleomycin, was found in the culture broth of Streptomyces verticillus var. pingyangensis n. var. [1], a bleomycins producing strain, which was isolated from a soil sample collected from Pingyang Area, Zhejiang Province, P.R. China. The present paper reports the fermentation, isolation, physico-chemical properties and structure elucidation of NC0604. The biological

H. Xu, R. Chen (Corresponding author), C. Chen, S. Si, Q. He, M. Lu, Y. Xie, Y. Wang: Institute of Medicinal Biotechnology, Chinese Academy of Medical Sciences \& Peking Union Medical College, Tian Tan Xi Li No 1, Beijing, 100050, P.R. China, chrx888@sohu.com,xhz882@sohu.com activities and pulmonary toxicity are also presented and compared with those of bleomycin.

A stock culture of the strain Streptomyces verticillus var. pingyangensis n.var. was grown and maintained on an agar slant consisting of glucose $1.0 \%$, soluble starch $1.0 \%$, peptone $0.5 \%$, agar $2.0 \%$, and $\mathrm{NaCl} 0.5 \%(\mathrm{pH} 7.2 \sim 7.5)$ at $28^{\circ} \mathrm{C}$. The stock culture was transferred into $250-\mathrm{ml}$ Erlenmeyer flasks containing $50 \mathrm{ml}$ of the seed medium consisting of soluble starch $2.5 \%$, glucose $0.5 \%$, soybean meal $3.5 \%, \mathrm{KH}_{2} \mathrm{PO}_{4} 0.1 \%, \mathrm{ZnSO}_{4} 0.05 \%$, and $\mathrm{CuSO}_{4}$ $0.01 \%(\mathrm{pH} 6.0 \sim 6.5)$. The culture was incubated on a rotary shaker (agitated at $220 \mathrm{rpm}$ ) at $28^{\circ} \mathrm{C}$ for 48 hours. Ten milliliters of the seed culture was transferred to $500-\mathrm{ml}$ Erlenmeyer flasks containing $100 \mathrm{ml}$ of the producing medium with the same components as the seed medium. The fermentation was carried out at $29^{\circ} \mathrm{C}$ for $7 \sim 8$ days on a rotary shaker at $220 \mathrm{rpm}$. Antibiotic activity in the fermentation broth was determined by paper-disk agar diffusion assay using Bacillus subtilis.

The fermentation broth (25 liters) was adjusted to $\mathrm{pH}$ $2 \sim 3$ with oxalic acid solution and filtered. The filtrate was charged on a column of 122 resins $\left(\mathrm{H}^{+}\right.$form, 1.0 liter $)$ which was washed with distilled water (2.0 liters) and then eluted with $0.3 \mathrm{M} \mathrm{HCl}$ (4.0 liters). The active fractions were combined, adjusted to $\mathrm{pH} 7.0$, and $0.2 \%(\mathrm{~m} / \mathrm{v}) \mathrm{CuSO}_{4}$ was added to the solution. The resulting solution was passed through a column of x-5 (2.0 liters) for desalting. Elution was carried out with $10 \% \mathrm{Me}_{2} \mathrm{CO}$ soln (containing $0.01 \mathrm{M}$ $\mathrm{HCl})$ and the eluates were combined and removed the $\mathrm{Me}_{2} \mathrm{CO}$ in vacuo. The active fractions (1.0 liter) were chromatographed on a column of CM-Sephadex C-25 $\left(\mathrm{NH}_{4}^{+}\right.$form, 1.0 liter) which was then eluted with $\mathrm{NH}_{4} \mathrm{Cl}$ solution with a concentration gradient from 0.1 to $0.5 \mathrm{M}$. The copper-chelated $\mathrm{NC} 0604$ was eluted with $0.2 \mathrm{M} \mathrm{NH}_{4} \mathrm{Cl}$ 
Table 1 Physico-chemical properties of NC0604

\begin{tabular}{ll}
\hline Appearance & White powder \\
Elemental composition reported by Q-TOF2 & $\mathrm{C}_{60} \mathrm{H}_{94} \mathrm{~N}_{20} \mathrm{O}_{22} \mathrm{~S}_{2}$ \\
ESI-Q-TOF2-MS Found & $1511.6379[\mathrm{M}+\mathrm{H}]^{+}$ \\
& Calcd 1511.6371 \\
$\mathrm{UV} \lambda_{\max }^{\mathrm{MeOH}} \mathrm{nm}(\varepsilon)$ & $243 \sim 245(\mathrm{sh}).(24,882), 292 \sim 295(16,479)$ \\
$\mathrm{IR} v_{\max }(\mathrm{KBr}) \mathrm{cm}^{-1}$ & $3385,1718,1653,1549,1054$ \\
Solubility & $\mathrm{H}_{2} \mathrm{O}, \mathrm{MeOH}$ \\
Color reaction & \\
$\quad$ Guanidino & Negative \\
Ninhydrin & Non-typical \\
\hline
\end{tabular}

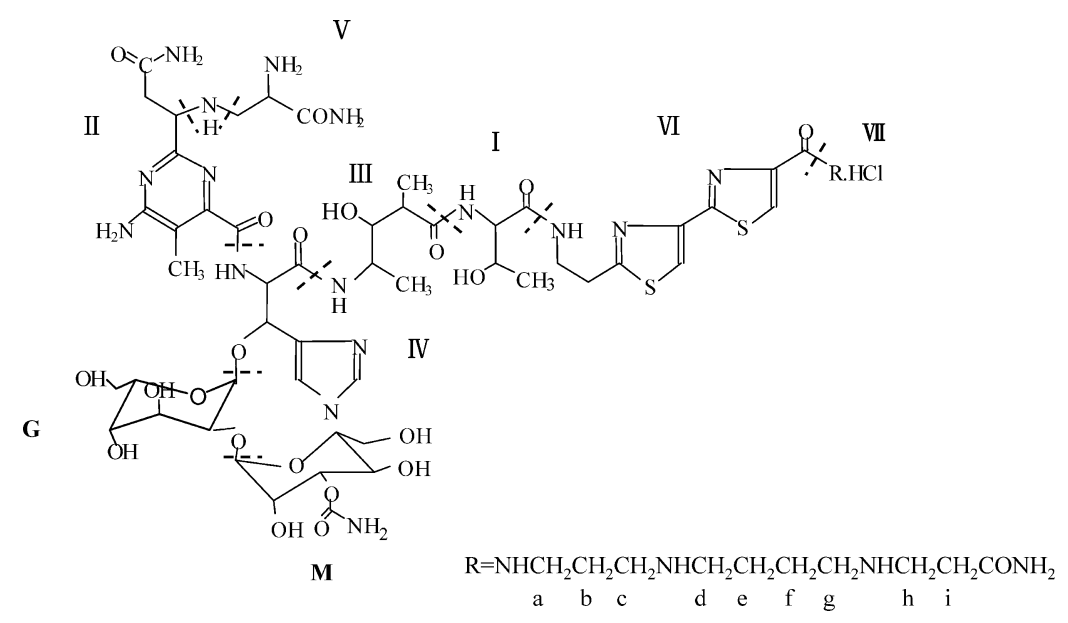

Fig. 1 Structure of NC0604

solution.

The fraction containing copper-chelated NC0604 was desalted with a column of $\mathrm{x}-5$, and the column then eluted with $10 \% \mathrm{Me}_{2} \mathrm{CO}$ soln (containing $0.01 \mathrm{M} \mathrm{HCl}$ ). The active eluate was concentrated in vacuo and lyophilized to afford a blue powder of copper-chelated NC0604 (313 mg). Finally, copper-free NC0604 was prepared by treatments with dithizone $(120 \mathrm{mg})$ in $\mathrm{MeOH}(10 \mathrm{ml})$. The solution was filtered, and the filtrate was precipitated with 4 times volume of $\mathrm{Me}_{2} \mathrm{CO}$. After washed with acetone for three times and filtered, the precipitate was dissolved in distilled water, concentrated in vacuo and lyophilized to give pure copper-free compound NC0604 (266 mg).

The physico-chemical properties of $\mathrm{NC} 0604$ are summarized in Table 1.

The copper-chelated NC0604 showed UV absorption maximum at $243 \sim 245 \mathrm{~nm}$ and at $292 \sim 295 \mathrm{~nm}$, respectively, and the intensity ratio of the two absorption maximum is 1.23 . As for copper-free preparation, absorption at $243 \sim 245 \mathrm{~nm}$ turned into a shoulder peak.
NC0604 showed a typical UV spectrum similar to that of bleomycin.

The IR spectrum indicated the presence of $\mathrm{OH} / \mathrm{NH}$ groups $\left(3385 \mathrm{~cm}^{-1}\right), \mathrm{C}=\mathrm{O}$ group $\left(1718 \mathrm{~cm}^{-1}\right), \mathrm{CONH}$ (1653 and $\left.1553 \mathrm{~cm}^{-1}\right)$ and $\mathrm{OH}$ group $\left(1050 \mathrm{~cm}^{-1}\right)$. These absorptions suggested that there was a glycopeptide structure in the molecule of the antibiotic.

The shift data of ${ }^{1} \mathrm{H}-\mathrm{NMR}$ spectrum of copper-free NC0604 at $\delta_{\mathrm{H}} 7 \sim 9 \mathrm{ppm}$ indicated four aromatic protons, which belonged to the thiazole ring and imidazole ring of the kernel structure of bleomycin molecule. They are valuable characteristics for identification of bleomycins.

We assigned the ${ }^{13} \mathrm{C}$ signals of $\mathrm{NC} 0604$ by comparison with ${ }^{13} \mathrm{C}$-NMR data of bleomycins reported previously [2, 3] and by analysis of ${ }^{1} \mathrm{H}_{-}{ }^{13} \mathrm{C}$ COSY, heteronuclear single quantum correlation (HSQC) and heteronuclear multiple bond correlation (HMBC) spectra of $\mathrm{NC} 0604$. The ${ }^{13} \mathrm{C}$ NMR spectral data are tabulated in Table 2 in comparison with those of bleomycin $\mathrm{A}_{2}$ presented in the previous paper [3]. The numbering of the parts in the NC0604 molecule 
Table $2{ }^{13} \mathrm{C}-\mathrm{NMR}$ data for NC0604 (150 MHz, $\mathrm{D}_{2} \mathrm{O}, \mathrm{pD}$ 6.2)

\begin{tabular}{|c|c|c|c|c|c|c|c|}
\hline & \multirow{2}{*}{ Assignment } & \multicolumn{2}{|c|}{${ }^{13} \mathrm{C}$ shift (ppm) } & & \multirow{2}{*}{ Assignment } & \multicolumn{2}{|c|}{${ }^{13} \mathrm{C}$ shift (ppm) } \\
\hline & & NC0604 & $\mathrm{BLM} \mathrm{A}_{2}{ }^{\mathrm{a}}$ & & & NC0604 & $\mathrm{BLM} \mathrm{A}_{2}$ \\
\hline \multirow[t]{4}{*}{ । } & $\mathrm{CO}$ & 175.9 & 172.5 & G & 1 & 100.3 & 98.3 \\
\hline & $\beta-\mathrm{CH}$ & 69.8 & 68.0 & & 2 & 73.1 & 71.0 \\
\hline & $\alpha-\mathrm{CH}$ & 61.9 & 59.9 & & 3 & 70.7 & 68.6 \\
\hline & $\mathrm{CH}_{3}$ & 21.7 & 20.0 & & 4 & 71.9 & 70.0 \\
\hline \multirow[t]{9}{*}{ ॥ } & $\mathrm{S}-\mathrm{CO}$ & 179.0 & 176.7 & & 5 & 69.8 & 68.0 \\
\hline & $\mathrm{R}-\mathrm{CO}$ & 170.5 & 168.3 & & 6 & 63.1 & 61.2 \\
\hline & 2 & 168.2 & 165.9 & $M$ & $\mathrm{CO}$ & 160.7 & 158.5 \\
\hline & 4 & 167.4 & 165.2 & & 1 & 101.0 & 98.8 \\
\hline & 6 & 155.0 & 152.9 & & 3 & 77.1 & 75.2 \\
\hline & 5 & 115.1 & 113.0 & & 5 & 76.4 & 74.4 \\
\hline & $\alpha-\mathrm{CH}$ & 62.6 & 60.5 & & 2 & 71.1 & 69.2 \\
\hline & $\beta-\mathrm{CH}_{2}$ & 43.0 & 41.0 & & 4 & 67.6 & 65.6 \\
\hline & $\mathrm{CH}_{3}$ & 13.7 & 11.9 & & 6 & 63.7 & 61.8 \\
\hline \multirow[t]{6}{*}{ III } & $\mathrm{CO}$ & 180.3 & 178.1 & VII (R) & (CO) & 177.5 & - \\
\hline & $\beta-\mathrm{CH}$ & 77.1 & 75.2 & & d & 49.8 & - \\
\hline & $\gamma-\mathrm{CH}$ & 50.7 & 48.5 & & $g$ & 49.7 & - \\
\hline & $\alpha-\mathrm{CH}$ & 45.4 & 43.5 & & $\mathrm{~h}$ & 46.1 & - \\
\hline & $\gamma-\mathrm{CH}_{3}$ & 17.5 & 15.8 & & c & 48.0 & - \\
\hline & $\alpha-\mathrm{CH}_{3}$ & 14.8 & 12.9 & & a & 39.1 & - \\
\hline \multirow[t]{6}{*}{ IV } & $\mathrm{CO}$ & 171.9 & 169.4 & & b & 28.6 & - \\
\hline & 2 & 139.8 & 137.4 & & i & 33.3 & - \\
\hline & 4 & 137.7 & 134.7 & & e & 25.7 & - \\
\hline & 5 & 120.5 & 118.6 & & f & 25.5 & \\
\hline & $\beta-\mathrm{CH}$ & 75.9 & 73.6 & & $\alpha-\mathrm{CH}_{2}$ & - & 41.8 \\
\hline & $\alpha-\mathrm{CH}$ & 59.8 & 57.7 & & $\gamma-\mathrm{CH}_{2}$ & - & 38.6 \\
\hline \multirow[t]{3}{*}{ V } & $\mathrm{CO}$ & 174.8 & 171.6 & & $\mathrm{CH}_{3} \times 2$ & - & $25.7 \times 2$ \\
\hline & $\alpha-\mathrm{CH}$ & 55.6 & 53.3 & & $\beta-\mathrm{CH}_{2}$ & - & 24.6 \\
\hline & $\beta-\mathrm{CH}_{2}$ & 50.3 & 47.8 & & & & \\
\hline \multirow[t]{9}{*}{ VI } & $\mathrm{CO}$ & 166.3 & 163.7 & & & & \\
\hline & 2 & 165.5 & 163.0 & & & & \\
\hline & $2^{\prime}$ & 173.4 & 171.0 & & & & \\
\hline & 4 & 151.6 & 149.4 & & & & \\
\hline & $4^{\prime}$ & 149.7 & 147.5 & & & & \\
\hline & $5^{\prime}$ & 121.9 & 119.8 & & & & \\
\hline & 5 & 127.9 & 125.7 & & & & \\
\hline & $\beta-\mathrm{CH}_{2}$ & 41.9 & 40.0 & & & & \\
\hline & $\alpha-\mathrm{CH}_{2}$ & 34.8 & 32.9 & & & & \\
\hline
\end{tabular}

a BLM $A_{2}$ : Bleomycin $A_{2}$ (pD 6, $25 \mathrm{MHz}$, ref 3).

follows the convention used in the previous paper [3] as shown in Fig. 1.

The signals of the carbons constituting the kernel structure of NC0604 are consistent with those of bleomycin $\mathrm{A}_{2}$. Therefore, we inferred that these two compounds are different from each other only in terminal amine moiety (R). Except for the signals of the carbons that constitute the
NC0604 skeleton, the remains were all assigned to the terminal amine moiety.

The ${ }^{1} \mathrm{H}-\mathrm{NMR}$ and ${ }^{1} \mathrm{H}-{ }^{1} \mathrm{H}$ COSY indicated the signal positions of the R moiety: R-a $\left(\delta_{\mathrm{H}} 3.58\right), \mathrm{R}-\mathrm{b}\left(\delta_{\mathrm{H}} 2.10\right), \mathrm{R}-$ c $\left(\delta_{\mathrm{H}} 3.21\right), \mathrm{R}-\mathrm{d}\left(\delta_{\mathrm{H}} 3.17\right), \mathrm{R}-\mathrm{e}\left(\delta_{\mathrm{H}} 1.85\right), \mathrm{R}-\mathrm{f}\left(\delta_{\mathrm{H}} 1.85\right), \mathrm{R}-$ $\mathrm{g}\left(\delta_{\mathrm{H}} 3.17\right)$, R-h $\left(\delta_{\mathrm{H}} 3.36\right), \mathrm{R}-\mathrm{i}\left(\delta_{\mathrm{H}} 2.79\right)$. The HSQC spectrum indicated that $\mathrm{R}-\mathrm{a}\left(\delta_{\mathrm{H}} 3.58\right)$ corresponded to a 
Table 3 Antimicrobial activity of NC0604

\begin{tabular}{lclc}
\multicolumn{1}{c}{ Test bacteria } & MIC $(\mu \mathrm{g} / \mathrm{ml})$ & \multicolumn{1}{c}{ Test bacteria } & MIC $(\mu \mathrm{g} / \mathrm{ml})$ \\
\hline Staphylococcus aureus ATCC29213 & 2 & Klebsiella pneumoniae 14 & 0.25 \\
Staphylococcus aureus 15 & 32 & Aerobacter cloacae 45031 & 1 \\
Staphylococcus aureus 05-3 (MRSA) & 64 & Enterobacter aerogenes 45102 & 1 \\
Staphylococcus epidermidis ATCC 12228 & 16 & Acinetobacter calcoaceticus 25001 & $>128$ \\
Staphylococcus epidermidis 04-5 (MRSE) & $>128$ & Bacillus proteus 49027 & 1 \\
Enterococcus faecalis ATCC 29212 & $>128$ & Shigella sonnei 51592 & 1 \\
Enterococcus faecalis 775 & 64 & Shigella dysenteriae & 0.25 \\
Escherichia coli ATCC 25922 & 0.5 & Shigella flexneri & 0.25 \\
Escherichia coli 26 & 1 & Bacillus typhi murium & 0.25 \\
Pseudomonas aeruginosa ATCC 27853 & $>128$ & Bacillus typhi H901 & 0.25 \\
Pseudomonas aeruginosa 17 & $>128$ & Bacillus subtilis 6633 & 0.03 \\
Klebsiella pneumoniae ATCC 700603 & 2 & & \\
\hline
\end{tabular}

signal at $\delta_{\mathrm{C}} 39.1, \mathrm{R}-\mathrm{b}\left(\delta_{\mathrm{H}} 2.10\right)$ to $\delta_{\mathrm{C}} 28.6, \mathrm{R}-\mathrm{c}\left(\delta_{\mathrm{H}} 3.21\right)$ to $\delta_{\mathrm{C}} 48.0, \mathrm{R}-\mathrm{d}\left(\delta_{\mathrm{H}} 3.17\right)$ to $\delta_{\mathrm{C}} 49.8, \mathrm{R}-\mathrm{e}\left(\delta_{\mathrm{H}} 1.85\right)$ to $\delta_{\mathrm{C}} 25.7$, R-f $\left(\delta_{\mathrm{H}} 1.85\right)$ to $\delta_{\mathrm{C}} 25.5, \mathrm{R}-\mathrm{g}\left(\delta_{\mathrm{H}} 3.17\right)$ to $\delta_{\mathrm{C}} 49.7, \mathrm{R}-\mathrm{h}\left(\delta_{\mathrm{H}}\right.$ $3.36)$ to $\delta_{\mathrm{C}} 46.1$, and R-i $\left(\delta_{\mathrm{H}} 2.79\right)$ to $\delta_{\mathrm{C}} 33.3$, respectively.

In the HMBC spectrum, the signal at $\delta_{\mathrm{C}} 39.1$ (R-a) showed a cross peak with a proton at $\delta_{\mathrm{H}} 2.10(\mathrm{R}-\mathrm{b}), \delta_{\mathrm{C}} 28.6$ (R-b) showed coupling to $\delta_{\mathrm{H}} 3.21$ (R-c) and $\delta_{\mathrm{H}} 3.58(\mathrm{R}-\mathrm{a})$, $\delta_{\mathrm{C}} 48.0(\mathrm{R}-\mathrm{c})$ to $\delta_{\mathrm{H}} 3.58(\mathrm{R}-\mathrm{a})$ and $\delta_{\mathrm{H}} 2.10(\mathrm{R}-\mathrm{b}), \delta_{\mathrm{C}} 49.8$ (R-d) to $\delta_{\mathrm{H}} 3.21(\mathrm{R}-\mathrm{c})$ and $\delta_{\mathrm{H}} 3.17(\mathrm{R}-\mathrm{g}), \delta_{\mathrm{C}} 25.7$ (R-e) to $\delta_{\mathrm{H}} 3.17(\mathrm{R}-\mathrm{d}), \delta_{\mathrm{H}} 1.85(\mathrm{R}-\mathrm{f})$ and $\delta_{\mathrm{H}} 3.17(\mathrm{R}-\mathrm{g}), \delta_{\mathrm{C}} 25.5(\mathrm{R}-$ f) to $\delta_{\mathrm{H}} 1.85(\mathrm{R}-\mathrm{e}), \delta_{\mathrm{H}} 3.17(\mathrm{R}-\mathrm{g})$ and $\delta_{\mathrm{H}} 3.17(\mathrm{R}-\mathrm{d}), \delta_{\mathrm{C}}$ $49.7(\mathrm{R}-\mathrm{g})$ to $\delta_{\mathrm{H}} 3.36(\mathrm{R}-\mathrm{h}), \delta_{\mathrm{C}} 46.1(\mathrm{R}-\mathrm{h})$ to $\delta_{\mathrm{H}} 2.79(\mathrm{R}-\mathrm{i})$, respectively. Moreover, the methylene of $\mathrm{R}-\mathrm{a}\left(\delta_{\mathrm{H}} 3.58\right)$ showed a cross peak with a signal at $\delta_{\mathrm{C}} 166.3$ (VI-CO) and the methylene signal at $\delta_{\mathrm{H}} 2.79\left(\mathrm{R}-\mathrm{i}-\mathrm{CH}_{2}\right)$ showed a cross peak with the carbonyl signal at $\delta_{\mathrm{C}} 177.5$ (R-CO). Therefore, the assignments for carbons of $\mathrm{R}$ moiety were determined as shown in Table 2 and the ${ }^{13} \mathrm{C}$-connectivities revealed by analysis of the HMBC spectrum are indicated with a bold line in Fig. 1.

NC0604 exhibited antibacterial activity against members of a wide range of bacterial species. The antibacterial activity of NC0604 is shown in Table 3. Better antibacterial activities were observed against members of Bacillus species and some Gram-negative bacteria.

Table 4 shows the growth-inhibitory activity in vitro of NC0604 toward human tumour cells. In comparison with that of bleomycin, NC0604 had a 3 to 9 times higher activity against tumour cells such as HepG2, KB, MCF-7, HCT116, BGC-823 and MCF-7/DOX.

The pulmonary toxicity for mice was determined in male Kunming mice. $10 \mathrm{mg} / \mathrm{kg}$ of the test compounds were injected intraperitoneally daily for 10 days. The pulmonary
Table 4 Activities $\left(\mathrm{IC}_{50}, \mu \mathrm{M}\right)$ of NC0604 in inhibiting the growth of cultured tumour cells

\begin{tabular}{lccc}
\hline \multicolumn{1}{c}{ Cells } & NC0604 (a) & Bleomycin (b) & Ratio (b/a) \\
\hline HepG2 & 1.18 & 7.87 & 6.67 \\
KB & 1.21 & 4.91 & 4.06 \\
MCF-7 & 1.41 & 3.66 & 2.60 \\
HCT116 & 1.83 & 8.24 & 4.50 \\
BGC-823 & 2.02 & 10.79 & 5.34 \\
MCF7/DOX & 1.45 & 13.30 & 9.17 \\
A549 & 8.71 & 8.01 & 0.92 \\
HL-60 & 19.67 & 29.69 & 1.51 \\
SK-OV-3 & 12.01 & 14.14 & 1.18 \\
\hline
\end{tabular}

toxicity was evaluated by determining the content of hydroxyproline (HYP) and observing the histopathological changes of the lung tissues at day 28 after administration of NC0604 and bleomycin, respectively. The content of HYP in the lung tissues treated with NC0604 was 1.4 times lower than that treated with bleomycin $(p<0.01)$. According to Ashcroft's [4] method, the degree of pulmonary fibrosis by $\mathrm{NC0604}$ was measured microscopically as grade $2 \sim 3$, showing moderate thickening of walls without obvious damage to lung architecture, while bleomycin was measured as grade $6 \sim 7$, meaning severe distortion of structure and large fibrous areas. Obviously, NC0604 had reduced pulmonary toxicity. 


\section{References}

1. Zhao Y, Xie M, Wang G. Studies on Zhengguangmycins. Taxonomy of Streptomyces verticillus var. pingyangensis n.var. Acta Microbiologica Sinica 19: 361 (1979)

2. Naganawa H, Kadokura Y, Muraoka Y, et al. Carbon-13 NMR assignment of peplomycin. J Antibiot 12: 633-636
(1989)

3. Naganawa H, Muraoka Y, Takita T, Umezawa H. Chemistry of bleomycin. XVIII. Carbon-13 NMR studies. J Antibiot 30: 388-396 (1977)

4. Ashcroft T, Simpson JM, Timbrell V. Simple method of estimating severity of pulmonary fibrosis on a numerical scale. J Clin Pathol 41: 467-470 (1988) 